\title{
Epidemiological, Clinical Aspects and Treatment of Victims of Sexual Abuse in the Gynecology and Obstetrics Department of Pikine National Hospital in 183 Cases
}

\author{
Moussa Diallo, Babacar Biaye*, Abdoul Aziz Diouf, Aminata Niass, Cyr Espérence Gombet, \\ Codou Sène, Anna Dia, Astou Coly Niassy Diallo, Fatoumata Bineta Diallo, \\ Hadja Maimouna Barro Daff, Khalifa Fall, Khalifa Gueye, Alassane Diouf
}

Gynecological and Obstetric Clinic of Aristide Hospital Le Dantec of Dakar, Dakar, Senegal

Email: *drbabacarbiaye@yahoo.fr

How to cite this paper: Diallo, M., Biaye, B., Diouf, A.A., Niass, A., Gombet, C.E., Sène, C., Dia, A., Diallo, A.C.N., Diallo, F.B., Daff, H.M.B., Fall, K., Gueye, K. and Diouf, A. (2020) Epidemiological, Clinical Aspects and Treatment of Victims of Sexual Abuse in the Gynecology and Obstetrics Department of Pikine National Hospital in 183 Cases. Open Journal of Obstetrics and Gynecology, 10, 558-570.

https://doi.org/10.4236/ojog.2020.1040050

Received: March 18, 2020

Accepted: April 20, 2020

Published: April 23, 2020

Copyright $\odot 2020$ by author(s) and Scientific Research Publishing Inc. This work is licensed under the Creative Commons Attribution International License (CC BY 4.0).

http://creativecommons.org/licenses/by/4.0/ (c) (i) Open Access

\begin{abstract}
Introduction: Sexual abuse or sexual assault is part of violence against women, as is physical violence, female genital mutilation and forced marriage. According to the Criminal Code, this is any sexual offense committed with violence, coercion, threat or surprise on the person of others. It is a criminal act punishable by the laws in force in almost every country in the world. Study Objectives: 1) draw up an epidemiological profile of female victims of sexual abuse; 2) develop the treatment protocol. Methodology: This is a 7-year descriptive retrospective study from January 1, 2010 to December 31, 2016 at the Center Hospitalier National de Pikine (Dakar). Included in this study were all of the patients admitted during our investigation period who were the victims of suspected or certain sexual abuse, with or without requisition. For each case, the following parameters were studied: the epidemiological characteristics (age, gestation, parity and place of residence), the circumstances of the attack (time and place), the characteristics of the aggressor (age, link with the victim, number of aggressor), the type of sexual contact, the possible lesions found during the physical examination (genital and extra-genital), the mode of admission, the delay of the consultation, the attitude after the sexual abuse, the gynecological and obstetrical status of the victim, the repercussions and psychological follow-up, the paraclinical assessment, the treatments administered. Data were collected using a survey form and analyzed with SPSS software. Results: During the study period, 183 victims of sexual abuse were received and treated at the level of our structure out of a total of 39,760 patients, representing a frequency of $0.46 \%$. The age of the victims varied between 2 and 36 years with an average of 13 years. The 11
\end{abstract}


to 15 age group was the most represented. Students were the most represented among victims of sexual abuse (87.4\%). Workers represented $9.3 \%$ of the victims. Infants made up $3.3 \%$ of the victims; the average age of the alleged attackers was 31 when they were known to their victim. Half of the victims (50.3\%) were in the pre-pubertal stage. Among those who were in genital activity (91 cases or 49.7\%), 16 cases of pregnancy were reported; which represented $8.7 \%$ of cases. Only $20.2 \%$ of victims had genital trauma. Prescription of emergency contraception was carried out for $47 \%$ of the victims who were in genital activity. After the clinical examination, $17 \%$ of the victims had received antibiotic prophylaxis. Conclusion: Sexual abuse is currently a real socio-cultural drama. Preventing them involves raising public awareness. Their management must be early and adapted in order to prevent sexually transmitted infections and psychological consequences.

\section{Keywords}

Sexual Abuse, Trauma, Care

\section{Introduction}

Sexual abuse is a global scourge and remains one of the universal prohibitions. This is a phenomenon that is growing steadily these days. The victims of these unnatural acts are not exclusively female; according to international literature, $10 \%$ to $30 \%$ of girls and $10 \%$ to $15 \%$ of boys under 18 years of age suffer from unwanted sexual practices [1]. In the United States of America, it is estimated that there are 250,000 new cases of child sexual abuse per year [2]. In France, 59,000 children were victims of sexual abuse in 2001, 23\% more than in 1999 [3]. In Senegal, this phenomenon mainly concerns minors and its extent has increased steadily over the years [4]. It is a silent drama that requires a better approach to its eradication. Any doctor in the exercise of his or her art may be confronted with a case of sexual abuse. For this reason, mastery of the anatomy of the female genital system, its physiological varieties and a good method of management are necessary because they also allow the judicial authority to enforce the law without harming anyone.

Senegal's particularity reflects above all the lack of public awareness of the need to use health facilities for case reporting and the influence of socio-cultural principles that make it a taboo subject.

\section{Methodology}

\subsection{Type of Study}

This is a descriptive retrospective study.

\subsection{Study Period}

It took place over a period of 7 years: from January 1, 2010 to December 31, 2016. 


\subsection{Inclusion Criteria}

Included in this study were all patients received during our investigation period at the Gynaecology and Obstetrics Department of the National Hospital Center of Pikine who had been the victim of suspected or certain sexual abuse and with or without judicial requisition.

\subsection{Non-Inclusion Criteria}

Not all patients who consulted for genital trauma without sexual abuse and those with incomplete records were included in our study.

\subsection{Parameters Studied and Data Analysis}

In each case, the following parameters were studied: epidemiological characteristics (age, gestation, parity and place of residence), circumstances of the assault (time and place), characteristics of the perpetrator (age, relationship to the victim, number of perpetrators), type of sexual contact, any lesions found during the physical examination (genital and extra-genital), the method of admission, the time limit for consultation, the attitude after sexual abuse, the gynaecological and obstetrical status of the victim, the impact and psychological follow-up, the paraclinical assessment, the treatments administered. The data were collected using a survey sheet and analyzed using the SPSS software.

\subsection{Ethical Approval}

This study has been approved by the local ethics committee.

\section{Results}

\subsection{Epidemiological Aspects}

\subsubsection{Frequency}

During the study period, 183 victims of sexual abuse were received and cared for at our hospital out of a total of 39,760 patients, representing a frequency of $0.46 \%$.

\subsubsection{Age}

The age of the victims ranged from 2 to 36 years with an average of 13 years. The 11 - 15 age group was the most represented (35\%) (Figure 1).

\subsubsection{Gesture and Parity}

Nulligest and nulliparous were the most represented with $94 \%$ and $95 \%$ of cases respectively.

\subsubsection{Place of Residence}

All of our patients (100\%) resided in the suburbs of Dakar.

\subsubsection{Distribution of Victims of Sexual Abuse by Occupation}

Students were the most represented among victims of sexual abuse (87.4\%). those with a job accounted for $9.3 \%$ of the victims. Infants constituted $3.3 \%$ of the victims. 


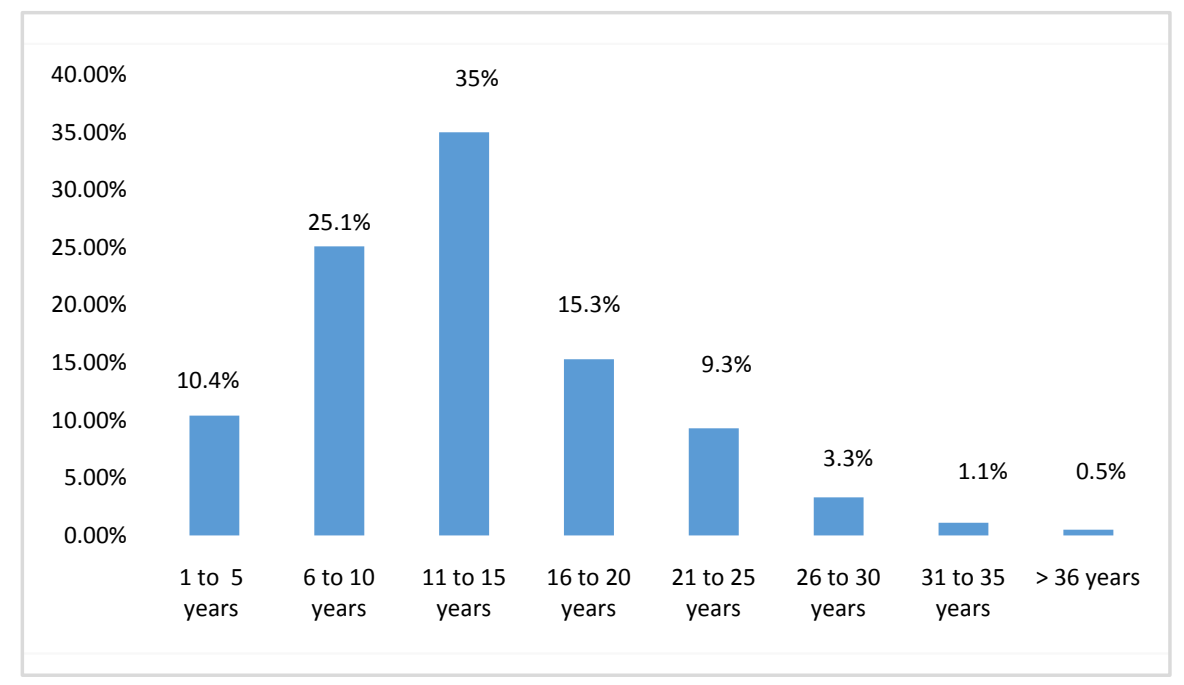

Figure 1. Distribution of victims of sexual abuse by age.

\subsection{Circumstances of the Aggression}

\subsubsection{Times and Locations of the Assault}

Sexual abuse occurred most often between 7a.m. and 6p.m. (23.5\%). It should be noted that for 100 cases $(54.6 \%)$, the time was not specified. More than half of sexual abuse (60.7\%) occurred outside the family. In $27.9 \%$ of cases, sexual abuse occurred in the home of the alleged abuser. In $30.6 \%$ of cases, sexual abuse took place in a public place, including schools, markets, houses under construction. In $2.2 \%$ of cases, the abuse occurred in the workplace of the alleged abuser, specifically in neighbourhood shops.

\subsubsection{Number of Abusers and Type of Sexual Contact}

In the majority of cases (92.4\%), sexual abuse was committed by a single individual. All the victims we had received in our structure reported a notion of genito-genital contact. Penetration was by far the most frequent type of sexual contact with an estimated $70.5 \%$ compared to 29 . Table 1: Cross table between the type of sexual contact and the age group 5\% for touching.

Until the age of 15, we see that the number of cases of sexual penetration increases gradually with the increase in the victim's age. Penetration was more frequent among victims aged 11 to 15 years. From the age of 16, we observe a decrease in the number of penetration cases becoming almost nil among victims over 30 years of age.

Sexual touching was more frequent among victims aged 1 to 15 years with a clear predominance of the 6 to 10 year age group. The number of sexual touching decreased with age, especially from the age of 16 . Among victims over 30 years of age, no cases were noted.

\subsubsection{Characteristics of the Aggressor and His Links with the Victim}

The average age of the alleged perpetrators was 31 years when they were known to their victims. For most of them, age was not specified (Table 2). 
Table 1. Cross table between the type of sexual contact and the age group.

\begin{tabular}{cccc}
\hline Age group & Touching & penetration & Total \\
\hline 1 to 5 years & 14 & 5 & 19 \\
6 - 10 years & 22 & 24 & 46 \\
11 to 15 years old & 10 & 54 & 64 \\
16 to 20 years old & 5 & 23 & 28 \\
21 to 25 years old & 2 & 15 & 17 \\
26 to 30 years old & 1 & 5 & 6 \\
31 to 35 years old & 0 & 2 & 2 \\
36 and over & 0 & 1 & 1 \\
Total & 54 & 129 & 183 \\
\hline
\end{tabular}

Table 2. Distribution of victims of sexual abuse by link with the alleged abuser.

\begin{tabular}{ccc}
\hline Relationship to the alleged attacker & Number & Percentage \\
\hline Family entourage & 21 & $11.5 \%$ \\
Parents & 9 & $5 \%$ \\
Lover & 10 & $5.4 \%$ \\
Figure of authority & 6 & $3.3 \%$ \\
Unknown & 137 & $74.8 \%$ \\
Total & 183 & $100 \%$ \\
\hline
\end{tabular}

For most victims, the perpetrators remained unknown (74.8\%). Only $25.2 \%$ of the assailants were known. It was a parent (father, brother, cousin, uncle) in 5\% of cases, a family member (roommate, neighbour, shopkeeper) in $11.5 \%$ of cases, a lover in $5.4 \%$ of cases or an authority figure (teacher, employer, "traditional healer") in $3.3 \%$ of cases.

\subsection{Clinical and Paraclinical Aspects}

\subsubsection{Mode of Admission}

Most victims had provided themselves with judicial requisition (79.2\%).

The majority of victims came to see a doctor before the fourth day after the assault (58.5\% of cases). We note extremes of one hour and one year. The judicial authority was the first place of consultation in $77.6 \%$ of cases.

\subsubsection{Consultation Period}

More than half of the patients had come for consultation in the first 72 hours (Table 3).

\subsubsection{Gynecological and Obstetrical Status}

Half of the victims (50.3\%) were in the pre-pubertal stage. Among those who were in genital activity (91 cases or $49.7 \%$ ), 16 cases of pregnancy were reported; this represented $8.7 \%$ of cases. 
Table 3. Distribution of victims of sexual abuse by time of consultation.

\begin{tabular}{ccc}
\hline Time to consultation & Number & Percent \\
\hline Until the 3rd day & 107 & $58.5 \%$ \\
$\mathbf{4}$ to 7 days & 26 & $14.2 \%$ \\
$\mathbf{8}-\mathbf{1 4}$ days & 13 & $7.10 \%$ \\
$\mathbf{1 5}$ to 30 days & 11 & $6 \%$ \\
$\mathbf{3 1}$ days and more & 26 & $14.2 \%$ \\
Total & 183 & $100 \%$ \\
\hline
\end{tabular}

\subsubsection{Number of Episodes of Sexual Abuse}

Repeated sexual abuse accounted for $19.7 \%$ of victims. Of these 36 cases of repeated sexual abuse, there were: 16 victims of sexual abuse twice (8.7\%); 5 victims of three episodes of sexual abuse (2.8\%) and 15 victims of more than three episodes of sexual abuse (8.2\%).

\subsubsection{Genital Trauma}

Only $20.2 \%$ of the victims had genital trauma. These were most often vulvar lesions $(18.6 \%)$ which were made of tearing $(7.1 \%)$, erosion $(7.1 \%)$ or inflammation (4.4\%) (Figure 2). Two cases of tearing of the Douglas cul-de-sac constituted vaginal lesions $(1.1 \%)$. One case of stabbing perineal tearing was noted. Figure 2 illustrates a rectovaginal communication following a sexual assault with the use of a stabbing weapon.

The majority of victims had hymen injuries (66.1\%). These lesions were mostly old (42.6\%). In $29.5 \%$ of cases, the hymen was intact and in $4.4 \%$ of cases, it was absent.

\subsubsection{Attitude of Victims after Sexual Abuse and Their Psychological Behavior}

The majority of victims had taken a shower (60.7\%) and changed clothes (64.5\%) before the consultation. The remaining $35 \%$ had come directly without showering or changing clothes (Table 4). The psychological state of the victims was apparently normal for most of them. Only $6 \%$ of the victims were anxious.

\subsubsection{Paraclinical Data}

Retroviral serology, HBs Antigenemia and syphilitic serology were requested in $89.6 \%, 90.1 \%$ and $89 \%$ of cases respectively. Vaginal sampling for bacteriological examination was requested in $80.3 \%$ of cases. A minority of victims (1.6\%) had benefited from a cytological study for sperm search (Table 5).

\subsection{Therapeutic Aspects}

Emergency contraception was prescribed for $47 \%$ of victims who were in genital activity. After the clinical examination, $17 \%$ of the victims had received antibiotic prophylaxis; $15.8 \%$ and $39.3 \%$ had received analgesic and antiseptic treatment respectively. Prevention of HIV infection by prescribing antiretrovirals was ef- 
fective in $17 \%$ of cases and antitetanus serovaccination concerned only $7.5 \%$ of them. Psychological care was provided to only $11.5 \%$ of victims. In terms of surgical management, $2.7 \%$ of victims had received it (Table 6).

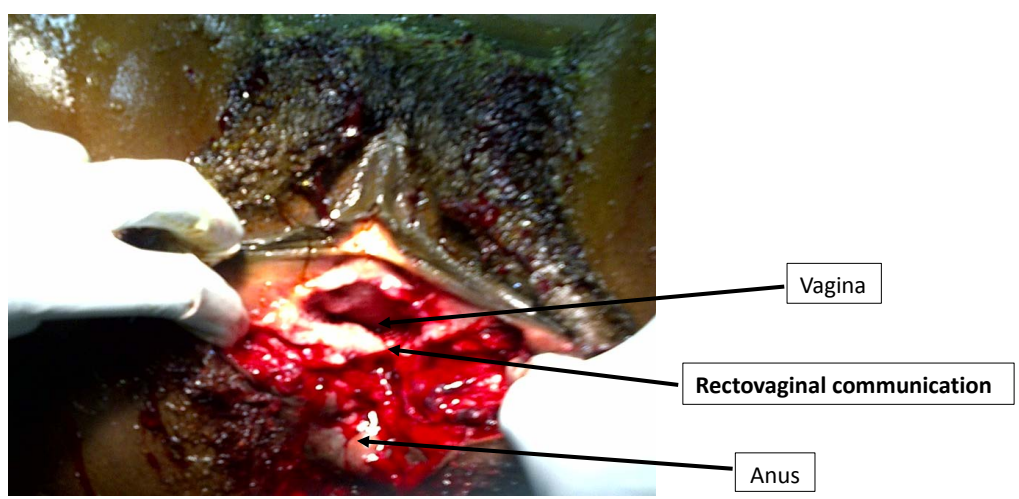

Figure 2. Attempted gang rape, followed by stabbing attack causing torn posterior perineum in 35-year-old woman.

Table 4. Distribution of victims of sexual abuse according to their attitudes after sexual abuse.

\begin{tabular}{ccc}
\hline Attitude after sexual abuse & Number & Percentage \\
\hline Change of clothes & 118 & $64.5 \%$ \\
Shower & 111 & $60.7 \%$ \\
Any & 64 & $35 \%$ \\
\hline
\end{tabular}

Table 5. Paraclinical assessment carried out among victims of sexual abuse.

\begin{tabular}{ccc}
\hline Requested blood test & Number & Percentage \\
\hline Retroviral serology & 164 & $89.6 \%$ \\
HBsAg & 165 & $90.1 \%$ \\
Syphilitic Serology & 163 & $89 \%$ \\
Vaginal sample & 147 & $80.3 \%$ \\
Cytological sample & 3 & $1.6 \%$ \\
No blood test & 17 & $9.3 \%$ \\
\hline
\end{tabular}

Table 6. Distribution of victims of sexual abuse by treatment.

\begin{tabular}{ccc}
\hline Treatment received & Number & Percentage \\
\hline Emergency contraception & $43 / 91$ & $47 \%$ \\
antiretrovirals & 31 & $17 \%$ \\
antibiotics & 31 & $17 \%$ \\
analgesics & 29 & $15.8 \%$ \\
antiseptics & 72 & $39.3 \%$ \\
Surgery & 5 & $2.7 \%$ \\
No treatment & 48 & $26 \%$ \\
Serum and tetanus vaccine & 13 & $7 \%$ \\
\hline
\end{tabular}




\section{Discussion}

\subsection{Frequency}

The frequency of sexual abuse represented $0.46 \%$ of all patients received during the study period. This value is almost identical to that obtained in 2006 in Senegal by Traoré [5] who reported a frequency of $0.4 \%$. This rate is relatively low compared to data from foreign literature; in France, the rate is reported to have increased from $0.8 \%$ to $1.2 \%$ between 1997 and 2000 [2]. In the United States, Lisak and Miller reported a 39\% incidence of sexual abuse in 2002 among the general population [6]. In Mali in 2002, Traoré noted a hospital frequency equivalent to $2.4 \%$ [5].

Senegal's particularity reflects above all the lack of public awareness of the need to use health facilities for case reporting and the influence of socio-cultural principles that make it a taboo subject.

\subsection{Age of Victim}

In our study, minors accounted for $81.4 \%$ of victims of sexual abuse. Those aged 11 to 15 years were more represented. The average age was 13 years. This high representativeness of minors was noted by several authors [7] [8] [9]. This is the case of Traoré, who had detected an average age of 14 years for victims [5]. In another study conducted by Cissé et al. in 2015, 92.64\% of victims were minors [4]. Mbaye [10] in 1990, in a study on child abuse in Senegal, made the same observation with a predominance of the 11 to 15 age group. According to Lisak [11] in France, the victims were most often aged between 3 and 6 years old and their average age was 9 years. For this phenomenon of sexual abuse, underage girls are therefore a vulnerable segment of society. This can be explained by the fact that they are immature, docile and easily manipulated, without any decision-making power. They are totally dependent and therefore subject to blackmail or threats that force them to submit to the abuser's wishes, especially if the abuser is a person with authority over them.

\subsection{Time of Sexual Abuse}

In more than half of the cases (54.6\%), the time of sexual abuse was not specified. Maybe because the victims being minors didn't know the clock. But also some victims who have suffered repeated sexual abuse (19.7\% of cases) at various times may have difficulty providing an accurate time. Among the victims, $23.4 \%$ were abused during working hours between $7 \mathrm{a} . \mathrm{m}$. and $6 \mathrm{p} . \mathrm{m}$. This observation was made by several authors [12] [13]. Why this rapprochement? Certainly because children at these times are separated from their parents due to their parents' professional constraints. Or even because the victims were at school, thus escaping parental control. A study was conducted in Yaoundé by Mbassa [14] in 2002 to estimate the prevalence of sexual abuse in schools and to clarify the actual participation of teachers; at the end of this study, the results were alarming: almost $15 \%$ of cases of sexual abuse had occurred in a school en- 
vironment and 30\% were perpetrated by classmates; teachers and tutors represented $7.9 \%$ and $7.3 \%$ of aggressors respectively. In South Africa, teachers have been found guilty of at least one-third of child rape [15]. In Senegal, a study carried out in some schools reveals that $62 \%$ of girls have been sexually abused [16]. According to Jaspard [17], the consequences for the girl are enormous: apart from injuries, pregnancies and clandestine abortions, there is also a lack of interest in school, fear of being laughed at by others, lowering the level, etc. These results support and make it necessary to set up a programme to prevent such acts in schools. It should also be noted that in our series, $19.7 \%$ of the abuses took place between 7 p.m. and 1 a.m., which is still not negligible. This means that the risk of sexual abuse is permanent, hence the importance of vigilance. This also reflects the insecurity in the suburbs of Dakar, which is exacerbated by the lack of public lighting and the idleness of young people, among others.

\subsection{Place of Sexual Abuse}

In our study, we found that sexual abuse often took place outside the family $(60.7 \%)$, perpetrated by a single person ( $92.3 \%$ of cases) often unidentified by the victim (74.9\%). The assailant was known in only $25.1 \%$ of cases: he was either a neighbour $(11.4 \%)$, a parent $(5 \%)$, a lover $(5.4 \%)$ or a figure of authority (employer, teacher, traditional healer) in $3.3 \%$ of cases. In France, Cazanave-Robert [18] is not going in this direction! According to his study, the family home was the main place where sexual abuse occurred and the often known perpetrators were in the family circle in the majority of cases $(48.2 \%)$. The intra-family origin of sexual abuse was a minority in our series (5\%); however, these figures may not reflect reality if we know that this aspect is on the one hand, often to preserve family balance, and on the other hand, it is strongly repressed by the society in which we live. The main problem with domestic violence is the difficulty of identifying it.

\subsection{Type of Sexual Contact}

Genito-genital contact remained the most frequent modality of sexual contact with a high vaginal penetration rate $(70.5 \%)$. Most of the minors $(65.8 \%)$ had undergone vaginal penetrations, especially those over 11 years of age. These rates are similar to those of Traoré [5] and Cissé [4] in Senegal, who had found $67.3 \%$ and $61 \%$ of vaginal penetrations respectively. This high rate of vaginal penetration among minors could be explained by the fact that they are easily manipulated and do not have the strength to resist such rape attempts. These results once again justify the need to systematically prevent the occurrence of sexually transmitted infections, HIV infection and unwanted pregnancies among victims of sexual abuse.

\subsection{Mode of Admission}

The interrogation revealed that most of the victims $(79.2 \%)$ had come to consult, 
with a judicial requisition. Diametrically opposed to Traorés results [5], in which only $15.2 \%$ of victims had come by requisition. Sexual abuse is an act condemned by Senegalese law, its perpetrators are subject to severe penalties. Denouncing the latter through the judicial authority is an effective means of eradicating this phenomenon because it makes it possible to avoid recurrences but also to deter potential aggressors. Victims should be further encouraged to report their aggressors to the judicial authority. Let us assume that in some cases of intra-family sexual abuse, it is extremely difficult for the victim to lodge a complaint against the perpetrator because there is a risk of reprisals or family dislocation.

\subsection{Time Limit for Consultation}

Victims most often came to see a doctor before the 4th day after the sexual abuse (58.5\%). This is not to be underestimated, but efforts to raise awareness still need to be made to reduce the delay, taking into account the need to prevent certain complications and to take samples in an emergency. Many victims suffer from this silent drama often because they are ashamed or want to preserve family balance when the perpetrator is a family member. The lack of knowledge of medical confidentiality is another factor that may explain this delay in consultation. Hence the need for information work with young people to gain their trust, but also the need to set up specialised structures to deal with cases of sexual abuse with the greatest discretion, such as medical and legal services [16].

\subsection{Type of Lesion}

In our series, several cases of genital trauma were noted. These were mainly hymen lesions (66.1\%) with old lesions predominating (42.6\%). This same observation was made by Traoré [5] in 2006, who had found $70.9 \%$ of hypermenial lesions with $54.5 \%$ being old. This is often explained by a longer consultation period in our context. Other vulvar (18.6\%), vaginal $(1.1 \%)$ and perineal $(0.5 \%)$ traumas are not to be neglected and should be sought if necessary on examination because they sometimes cause bleeding.

\subsection{Psychological Behavior of the Victim}

The psychological behavior of the victims was considered apparently normal for most (94\%). The few victims affected by anxiety were pre-pubescent $(1.6 \%)$, the others $(4.5 \%)$ older were in genital activity. These misleading appearances would explain the low rate of victims (11.5\%) who received psychological care. But knowledge of the real risk of psychological repercussions in the long term, leading to, among other things, social conduct disorders, would allow practitioners to give an important place to psychological care [19]. The Hamilton Anxiety Scale (Appendix 2) is a very important diagnostic tool to provide much more precision on the level of anxiety of victims. It would also be interesting to experiment with certain models of psycho-social care for victims of incest [2] based 
on their grouping into an association where they are received with compassion, allowing them, through projects and activities, to regain their self-esteem and dignity in order to reintegrate into society [18].

\subsection{Paraclinical Assessment}

More than $80 \%$ of the victims had received retroviral serology, HBs Antigenemia, syphilitic serology and vaginal sampling for mycoplasma and chlamydia. This is due to the high rate of vaginal penetration. Cytological samples are rarely requested (1.6\%) perhaps because most of the victims had taken a shower $(60.7 \%)$ or the sexual assault was old. As for the results of the initial assessment and the three-month HIV serology tests, none were mentioned. This is certainly due to the fact that once the certificate of medical expertise was issued, almost all the victims were lost sight of because they were much more interested in the judicial aspect than in therapeutic care. And in the absence of defloration, they were no longer interested in the medical aspect. This same aspect was found by Sy [19] who found that less than half (48.8\%) of sexual assault victims returned for follow-up assessment.

\subsection{Treatment}

In our study, $17 \%$ of victims had received antiretroviral prophylaxis. This rate seems relatively low compared to the percentage of penetration victims. This is just because some victims came after the effective triple therapy period was over. However, many cases of HIV/AIDS infection after rape have been reported, particularly by Marsaud [1] in South Africa (78\%). Hence the need once again to raise awareness to reduce consultation times.

Antibioprophylaxis was prescribed in $17 \%$ of cases. It must then be guided by the results of the samples, which must be available at short notice.

Almost all of the victims who received surgical care $(2.7 \%)$ had not yet reached puberty age, making them more vulnerable to trauma due to their sexual immaturity.

Only $23.5 \%$ of our patients had received emergency contraception, thus avoiding the risk of unwanted pregnancy, unlike others (8.7\%) who were forced to carry their pregnancies to term since voluntary termination of pregnancy is prohibited by Senegalese legislation according to article 35 of the Code of Ethics [4] [7] [11] which stipulates that "therapeutic abortion may only be performed if this intervention is the only way to save the mother's life". But we note that in recent years in Senegal, struggles have been waged by non-governmental organizations and some civil society organizations for the legalization of abortion. For these activists, legalizing abortion will reduce the number of maternal deaths due to clandestine abortions and also reduce the number of cases of infanticide. Another key issue for advocates of legalizing abortion is Senegal's ratification of the Maputo Protocol in its article 14 (2003), which would oblige our country to allow abortion for women who are victims of rape and incest or whose lives are 
threatened because of the pregnancy they carry. In this case, how could the practitioner state with certainty that the alleged victim was actually a victim of rape or should he or she only be satisfied with the speech of the alleged victim? We must accept that opening such a gap risks seeing all possible and imaginable abuses [13]. It would therefore be necessary above all to lead the fight against sexual abuse, to raise awareness among the population of the need for early consultations to ensure better care. The constitution of our country in its article 7 stipulates that: The human person is sacred. It is inviolable. The state has an obligation to respect and protect it. Everyone has the right to life, liberty, security, the free development of his personality, bodily integrity, including protection against all forms of physical mutilation. Life, the beginning of which is dated from conception, is a long process made up of multiple movements and sequences, each as important as the next. From the moment the male and female gametes meet, there is no more discontinuity between this first moment of fertilization and what each of us has become to this day [12]. In other words, if this process were interrupted for all of us, humanity would be devastated today. This is also why any damage to an embryo, whatever its age of gestation, could be considered as an attack against a human being and against humanity as a whole [15].

\subsection{Limits of the Study}

One of its limitations is the retrospective nature of the study. The examination is not carried out by a single staff.

\section{Conclusions}

Sexual abuse is a complex and ubiquitous phenomenon. Based on its current definition on the principle of consent, it enshrines the possibility of the individual to decide on his (non)-engage in sexual activity, and identifies a category of people who cannot validly use this faculty: children, who therefore deserve to be subject to special protection against sexual interactions in which adults would engage them and who, in all cases, will be considered sexual abuse.

The care requires multidisciplinary coordination. Vigorous enforcement of the law will help reduce the scourge.

\section{Conflicts of Interest}

The authors declare no conflicts of interest regarding the publication of this paper.

\section{References}

[1] Marsaud, O. (2001) Rape, Plagues of South African Schools. WHO, Geneva, 222-230

[2] Tjaden, P. and Thoennes, N. (2000) Full Report of the Prevalence, Incidence, and Consequences of Violence against Women: Findings from the National Violence 
against Women Survey. National Institute of Justice, Washington DC. https://doi.org/10.1037/e514172006-001

[3] Berger, D. (2000) Sexual Violence: What to Do in the Presence of a Victim of Sexual Assault. In: Updates in Obstetrics Gynecology, National College of French Gynecologists and Obstetricians, Éditions Vigot, Paris, 282-284.

[4] Cisse, C.T., Niang, M.M., Sy, A.K., Faye, E.H.O. and Moreau, J.C. (2015) Epidemioclinical, Legal and Cost Aspects of the Management of Sexual Abuse among Minors in Dakar, Senegal. Journal of Obstetrics Gynecology and Reproductive Biology, 44, 825-831. https://doi.org/10.1016/j.jgyn.2014.10.010

[5] Traoré, A.M. (2001) Sexual Violence: Clinical Aspects in Gynecological Consultation in the Gyneco-Obstetrics Department of Gabriel Touré Hospital Regarding 115 Cases. Doctoral Thesis in Medicine, University of Bamako (Mali), Bamako, 112.

[6] Barret, P. (2004) Sexual Assault. CNGOF Update, Paris, 275-281.

[7] Agossou, T. (2000) Perspectives from Africa on Mistreatment. Chapter 7, Chapter 19, Karthala Publishing, Paris, 77-87+188-198.

[8] Soutoul, J., Bertrand, J. and Body, G. (1980) Trauma to the Genital Tract and Perineum in Women. EMC Gynecology Elsevier, Paris, 4, 190A.

[9] Bugs, S. (2000) Contraception, IVG, Pregnancy: Question of Abortion and the New Crusaders of the Moral Order Grenoble. Thot Edition, 242.

[10] Mbaye, I. (1990) Child abuse in Senegal. These Med Dakar, 84.

[11] Lisak, D. and Miller, P. (2002) Repeat Rape and Multiple Offending among Undetected Rapists: Violence and Victims. American Journal of Obstetrics \& Gynecolo$g y$, 17, 73-84. https://doi.org/10.1891/vivi.17.1.73.33638

[12] Diallo, T.S., Konaré, K., Sy, A., Ndiaye, S.M., Dembélé, D.S., Nakoulima, A., Dionne, P. and Moro, M.R. (2019) Sexual Abuse of Children in Senegal: When Psychosocial Factors Impede the Repair Process. The Wild Thought, 20, 81-89. https://doi.org/10.3917/lautr.058.0081

[13] Japhet Pobanou Théra, M.T., Soumah, M., Traoré, T., Touré, M. and Sow, M.L. (2014) Epidemi-Clinical and Judicial Aspects of Sexual Assault in Mali. Public Health, 26, 123-29. https://doi.org/10.3917/spub.137.0123

[14] Mbassa, M. and Ngoh, F. (2003) Seroprevalence of HIV Infection in Child Victims of Sexual Abuse in Cameroon. Medicine Tropical, 63, 155-158.

[15] Daligaud, L. and Gonin, B. (1999) Sexual Violence. Journal of Andrology, 9, 519-527. https://doi.org/10.1007/BF03034671

[16] Faye, D.M.E., Traoré, A.L., Gueye, S.M.K., Moreira, P.M., Diouf, A. and Moreau, J.C. (2008) Epidemioclinical Profile and Management of Victims of Sexual Abuse at the Gynecological and Obstetric Clinic of the Dakar UHC, 2003-2005 Period. Journal of Obstetric Gynecology and Reproductive Biology, 37, 358-364. https://doi.org/10.1016/j.jgyn.2007.11.002

[17] Jaspard, M. (2001) Naming and Counting Violence against Women: A First National Survey in France. Population and Society, 364, 1-4.

[18] Cazanave-Robert, A. and Millot, C. (2003) Consideration and Setting up of a Reception Framework for Children Victims of Sexual Abuse at St-Vincent-de-Paul. Annale Francaise de Psychologie, 105-110.

[19] Sy, O. (2009) Inventory of the Medical, Psychological and Legal Care of Child Victims of Sexual Abuse Received at the Keur Xaleyi Child Psychiatry Unit of the Fann Teaching Hospital. These Med Dakar, 94. 